\title{
Methotrexate Discontinuation and Dose Decreases After Therapy With Tocilizumab: Results From the Corrona Rheumatoid Arthritis Registry
}

\author{
Dimitrios A. Pappas - Taylor Blachley · Steve Zlotnick • \\ Jennie Best · Kelechi Emeanuru · Joel M. Kremer
}

Received: January 27, 2020 / Published online: March 30, 2020

(C) The Author(s) 2020

\begin{abstract}
Introduction: Similar outcomes have been observed between patients with rheumatoid arthritis (RA) responding to tocilizumab (TCZ) with methotrexate (MTX) who discontinued vs. continued MTX and between patients receiving MTX who added TCZ vs. switched to TCZ monotherapy. This study examined MTX discontinuation and dose decreases in patients with RA initiating TCZ in a real-world setting.

Methods: TCZ-naïve patients enrolled in the Corrona RA registry who initiated TCZ in combination with MTX and had a 6-month followup visit without TCZ discontinuation were included. Patients were grouped by MTX dose at
\end{abstract}

Digital Features To view digital features for this article go to: https://doi.org/10.6084/m9.figshare.11949234.

D. A. Pappas $(\bowtie)$

Columbia University, New York, NY, USA

e-mail: dpappas@corrona.org

D. A. Pappas · T. Blachley · K. Emeanuru .

J. M. Kremer

Corrona, LLC, Waltham, MA, USA

S. Zlotnick · J. Best

Genentech, Inc., South San Francisco, CA, USA

J. M. Kremer

Albany Medical College, Albany, NY, USA

J. M. Kremer

The Center for Rheumatology, Albany, NY, USA the time of TCZ initiation $(\leq 10 \mathrm{mg},>10$ to $\leq 15 \mathrm{mg},>15$ to $\leq 20 \mathrm{mg},>20 \mathrm{mg}$ ). The primary outcome was the proportion of patients with changes in MTX use at 6 months, with a secondary analysis at 12 months. Changes in disease activity [Clinical Disease Activity Index (CDAI)] and patient-reported outcomes (PROs) at 6 and 12 months were summarized descriptively.

Results: Of 444 included patients, $82.7 \%$ were female and $83.7 \%$ white, with mean (SD) disease duration of 11.6 (9.3) years, baseline CDAI score of 24.0 (15.4), and baseline MTX dose of 17.7 (5.8) mg. At 6 months, 139 patients (31.3\%) discontinued or decreased their MTX dose. All MTX dose groups and patients who discontinued, decreased, maintained, or increased their MTX dose displayed improvements in CDAI scores and PROs at 6 months. Similar patterns and results were observed at 12 months.

Conclusions: A considerable proportion of patients initiating TCZ discontinued or decreased their MTX dose after TCZ initiation. Improvements in disease activity and functionality were observed in patients who decreased or stopped MTX. This real-world study confirmed prior observations that discontinuing or decreasing MTX may be a treatment strategy for patients initiating TCZ combination therapy.

Trial Registration: ClinicalTrials.gov identifier, NCT01402661. 


\section{PLAIN LANGUAGE SUMMARY}

Rheumatoid arthritis (RA) is a long-term disease that causes joint swelling, stiffness, and pain. Unless RA is treated quickly, patients can experience joint damage and disability. Patients with RA often take methotrexate (MTX) as their first treatment, but many patients do not have sufficient improvement with MTX alone. For these patients, doctors often add another medicine called a biologic to their existing treatment. However, taking more medications is associated with toxic effects and can make it harder for patients to stay on their therapy.

Tocilizumab (TCZ) is a biologic that is used to treat RA. In one clinical trial, reported by Kremer et al., patients whose RA improved when they were taking TCZ plus MTX were subsequently able to stop taking MTX and their RA remained well controlled (Arthritis Rheumatol 70(8):1200-1218, 2018). However, researchers had not looked at whether patients outside of a clinical trial (in the "real world") can stop taking MTX or take less MTX after they start taking TCZ. This study used real-world data to examine if patients who start taking TCZ subsequently stop taking or take less MTX.

This study showed that many patients were able to stop taking or take less MTX during the year after they started taking TCZ. Patients who stopped or decreased their MTX dose had lessactive RA and reported that they felt better and had fewer symptoms. These results suggest that it is common for patients in the real world to stop taking or take less MTX after they start taking TCZ.

Keywords: Methotrexate; Registry; Rheumatoid arthritis; Tocilizumab

\section{Key Summary Points}

\section{Why carry out this study?}

Patients with rheumatoid arthritis (RA) often continue receiving methotrexate (MTX) or other conventional synthetic disease-modifying antirheumatic drugs when initiating biologics; however, receiving an increased number of medications is associated with additive toxicities and impaired adherence to therapy.

\section{A randomized controlled trial} demonstrated that outcomes are comparable in patients responding to tocilizumab (TCZ) in combination with MTX who subsequently discontinue or continue MTX; however, the frequency of such therapy changes in routine clinical practice and whether TCZ can decrease the need for concomitant MTX remains unknown.

We examined MTX discontinuation and dose decreases in patients with RA initiating TCZ in a real-world observational registry.

\section{What was learned from this study?}

In this real-world population of patients with RA, a substantial proportion of patients were able to discontinue or decrease their dose of MTX over 6 months after TCZ initiation, and demonstrated improvements in disease activity and patient-reported outcomes, with similar changes observed at 12 months.

These results suggest that discontinuation or decreases in MTX dose after TCZ initiation are common in real-world practice. 


\section{INTRODUCTION}

Rheumatoid arthritis (RA) is a chronic autoimmune disease that is characterized by joint swelling, stiffness, and pain and progressive destruction of synovial joints [1]. Without prompt and effective disease-suppressing therapy, joint damage and disability result $[1,2]$. Conventional synthetic disease-modifying antirheumatic drugs (csDMARDs) are the recommended first-line treatment for patients with RA, with methotrexate (MTX) being the most frequent choice of initial csDMARD [2, 3]. However, a substantial proportion of patients with RA have an inadequate response to or are intolerant of MTX [2, 4-6].

In patients with an inadequate response to csDMARDs, addition of another csDMARD or a biologic is recommended [2, 3]. In most cases, a biologic is initiated as combination therapy with the initial csDMARD [2, 3]; however, receiving an increased number of medications is associated with additive toxicities and impaired adherence to therapy [7-10], which has been suggested to be a substantial problem in patients with RA $[11,12]$.

Tocilizumab (TCZ) is a monoclonal antibody that blocks the interleukin-6 (IL-6) receptor and is approved for the treatment of RA in patients who have had an inadequate response to csDMARDs [13]. TCZ is approved for use as monotherapy or in combination with other csDMARDs. TCZ monotherapy has been shown to be more effective than MTX monotherapy and has comparable efficacy to TCZ administered in combination with either MTX or other csDMARDs [14-16].

Thus far, a randomized controlled trial of MTX withdrawal in patients responding to TCZ plus MTX demonstrated that TCZ as monotherapy was clinically noninferior to continued use of TCZ plus MTX [17]. However, the frequency of such changes in therapy in the real world, and the extent to which TCZ can decrease the need for concomitant MTX use in routine clinical practice, remains unknown. Therefore, we examined MTX discontinuation and dose decreases in patients with RA initiating TCZ in a real-world setting. We also descriptively summarized disease activity and outcomes data for patients who either discontinued, decreased, or increased their dose of MTX and patients who continued a stable MTX dose.

\section{METHODS}

\section{Study Setting}

Data were obtained from the Corrona RA Registry, an ongoing, independent, prospective, observational cohort of patients with RA (NCT01402661) [18, 19]. Patients were recruited from 182 private and academic practice sites across 42 states in the United States, with 781 participating rheumatologists. As of June 2019, data on 52,737 patients with RA had been collected. The Corrona database includes information from 397,236 patient visits and 188,161 patient-years of follow-up observation time. The mean duration of patient follow-up is 4.5 years (median, 3.3 years).

\section{Patient Population and Data Collection}

The study population included patients aged $\geq 18$ years with RA enrolled in the Corrona RA registry who initiated TCZ while maintaining an existing MTX regimen at TCZ initiation and had a follow-up visit at 6 months ( \pm 3 months) after initiation without discontinuation of TCZ. Secondary analysis included patients with a 12-month ( \pm 3 months) follow-up visit without discontinuation of TCZ. Patients must have had a valid MTX dose recorded at the time of TCZ initiation and follow-up. Patients were stratified by weekly MTX dose at the time of TCZ initiation $(\leq 10 \mathrm{mg},>10$ to $\leq 15 \mathrm{mg},>15$ to $\leq 20 \mathrm{mg},>20 \mathrm{mg}$ ). Data from Corrona were collected from physician and patient questionnaires completed during routine clinical encounters that occurred over the study period. Data within Corrona that were recorded at the time of clinical encounter have been described previously and include patient demographics, clinical characteristics, history of comorbidities, current and prior medication use, clinical 
disease activity measures, and patient-reported outcome (PRO) measures [18].

Ethics approvals for this study were obtained from a central institutional review board (IRB; New England Independent Review Board No. 120160610). For academic investigative sites that did not receive a waiver to use the central IRB, full board approval was obtained from the respective governing IRBs and documentation of approval was submitted to the sponsor prior to initiating any study procedures. All procedures performed in studies involving human participants were in accordance with the ethical standards of the institutional and/or national research committee and with the 1964 Helsinki Declaration and its later amendments or comparable ethical standards. Informed consent was obtained from all individual participants included in the study.

\section{Study Design and Outcomes}

This was a retrospective, observational study to evaluate the patterns of MTX use after initiation of TCZ in patients with RA. The primary outcome was the proportion of patients with changes in MTX use (discontinuation or dose escalation or decrease $\geq 5 \mathrm{mg}$ ) from baseline to 6 months ( \pm 3 months). Secondary outcomes included the proportion of patients with changes in MTX use from baseline to 12 months ( \pm 3 months). Mean changes in disease activity and PRO measures at 6 and 12 months were also described. Disease activity measures included Clinical Disease Activity Index (CDAI), Disease Activity Score in 28 joints (DAS28), tender and swollen joint counts, and physician global assessment. PROs included patient global assessment; modified Health Assessment a

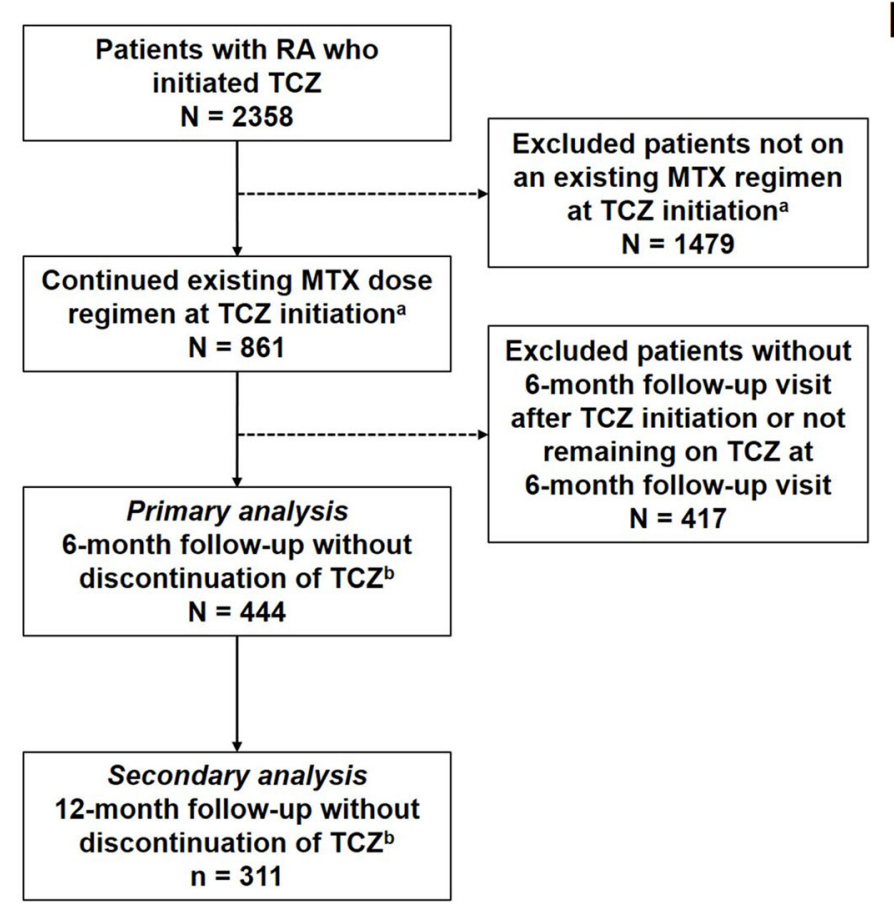

b

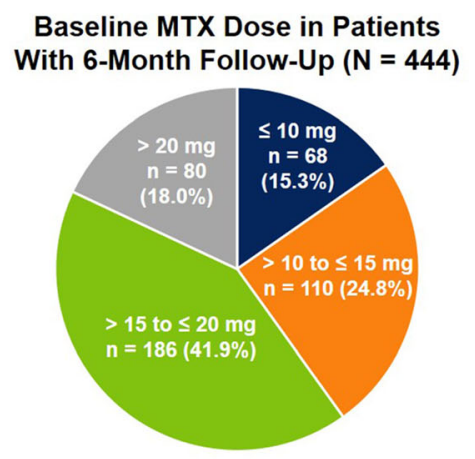

Baseline MTX Dose in Patients With 12-Month Follow-Up ( $\mathrm{N}=311)$

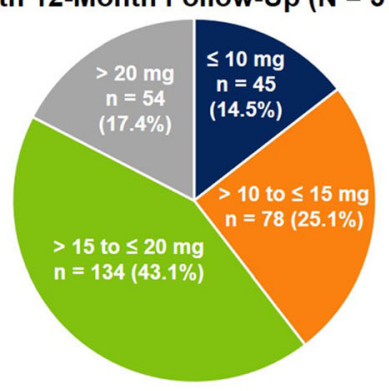

Fig. 1 Patient disposition. a Study population selection. b Baseline MTX dose distribution among patients included in the 6-month (primary) and 12-month (secondary) analyses. ${ }^{2}$ Patients must have had valid MTX dose information available and must have not been receiving other csDMARDs at TCZ initiation. ${ }^{\mathrm{b}}$ Patients remaining on MTX at follow-up must have had valid MTX dose information available at the follow-up visit. csDMARD conventional synthetic disease-modifying antirheumatic drug, MTX methotrexate, $R A$ rheumatoid arthritis, $T C Z$ tocilizumab 
Table 1 Baseline demographics, clinical characteristics, treatment profile, and disease activity for patients with RA who initiated TCZ with MTX

\begin{tabular}{|c|c|}
\hline Characteristics & $\begin{array}{l}\text { All TCZ initiators } \\
(N=444)\end{array}$ \\
\hline Age, mean $(\mathrm{SD})$, years & $57.3(12.7)$ \\
\hline Female, $n(\%)$ & $367(82.7)$ \\
\hline \multicolumn{2}{|l|}{ Race, $n$ (\%) } \\
\hline White & $369(83.7)$ \\
\hline Black & $21(4.8)$ \\
\hline Asian & $11(2.5)$ \\
\hline Other & $40(9.1)$ \\
\hline \multicolumn{2}{|l|}{ Smoking status, $n(\%)$} \\
\hline Current & $67(15.2)$ \\
\hline Previous & $130(29.5)$ \\
\hline Never & $244(55.3)$ \\
\hline Weight, mean (SD), lb & $185.5(50.3)$ \\
\hline \multicolumn{2}{|l|}{ BMI category, $n(\%)$} \\
\hline $\begin{array}{l}\text { Normal/underweight }(<25 \mathrm{~kg} / \\
\left.\mathrm{m}^{2}\right)\end{array}$ & $105(23.6)$ \\
\hline $\begin{array}{l}\text { Overweight }(\geq 25 \text { to }<30 \mathrm{~kg} / \\
\left.\mathrm{m}^{2}\right)\end{array}$ & $131(29.5)$ \\
\hline Obese $\left(\geq 30 \mathrm{~kg} / \mathrm{m}^{2}\right)$ & $208(46.8)$ \\
\hline \multicolumn{2}{|l|}{ Insurance, $n(\%)^{a}$} \\
\hline Private & $338(76.1)$ \\
\hline Medicaid & $22(5.0)$ \\
\hline Medicare & $158(35.6)$ \\
\hline None & $4(0.9)$ \\
\hline Disease duration, mean (SD), years & $11.6(9.3)$ \\
\hline \multicolumn{2}{|l|}{ History of comorbidities, $n$ (\%) } \\
\hline Hypertension & $131(29.5)$ \\
\hline Diabetes & $49(11.0)$ \\
\hline Malignancy $^{\mathrm{b}}$ & $35(7.9)$ \\
\hline
\end{tabular}

Table 1 continued

\begin{tabular}{ll}
\hline Characteristics & All TCZ initiators \\
& $(N=444)$
\end{tabular}

Cardiovascular disease $^{c} \quad 160(36.0)$

No. of prior non-MTX csDMARDs, $n(\%)^{\mathrm{d}, \mathrm{e}}$

$$
\begin{array}{lr}
0 & 240(54.1) \\
1 & 109(24.5) \\
\geq 2 & 95(21.4)
\end{array}
$$

No. of prior biologics, $n(\%)^{\mathrm{d}, \mathrm{f}}$

0

1

$123(27.7)$

$\geq 2$

$295(66.4)$

Current prednisone use, $n$ (\%)

$158(35.6)$

Prednisone dose, mean (SD), $\mathrm{mg}^{\mathrm{g}} \quad 7.1$ (5.4)

MTX dose, mean (SD), mg

$17.7(5.8)$

CDAI score, mean (SD)

$24.0(15.4)$

DAS28, mean (SD)

$4.3(1.6)$

$8.8(8.1)$

Tender joint count $(0-28)$, mean (SD)

Swollen joint count (0-28), mean (SD)

Physician global assessment (VAS

$38.5(22.2)$

$0-100)$, mean (SD)

Patient global assessment (VAS 50.2 (25.5)

$0-100)$, mean $(\mathrm{SD})$

mHAQ, mean (SD) $\quad 0.6(0.5)$

Patient pain (VAS 0-100), mean 52.3 (26.2) (SD)

Patient fatigue (VAS 0-100), mean 55.0 (27.9) (SD)

Morning stiffness present, $n$ (\%) $\quad 368$ (89.8) 
Table 1 continued

\section{Characteristics}

All TCZ initiators

$(N=444)$

Morning stiffness duration, mean

$1.9(3.2)$

(SD), $\mathrm{h}^{\mathrm{h}}$

$B M I$ body mass index, $C A B G$ coronary artery bypass grafting, $C D A I$ Clinical Disease Activity Index, $C H F$ congestive heart failure, $c s D M A R D$ conventional synthetic disease-modifying antirheumatic drug, $C V$ cardiovascular, $D A S 28$ Disease Activity Score in 28 joints, $m H A Q$ modified Health Assessment Questionnaire, $M T X$ methotrexate, $R A$ rheumatoid arthritis, $T C Z$ tocilizumab, $V A S$ visual analog scale

a Totals may not add up to $100 \%$ since patients may have had $>1$ type of insurance

b Malignancy includes breast cancer, lung cancer, lymphoma, skin cancer (melanoma and squamous cell), and other cancers

c History of cardiovascular disease includes history of hypertension, hyperlipidemia, cardiac revascularization procedure (CABG, stent, angioplasty), ventricular arrhythmia, cardiac arrest, myocardial infarction, acute coronary syndrome, unstable angina, other coronary artery disease, CHF (with and without hospitalization), stroke, transient ischemic attack, other $\mathrm{CV}$, deep vein thrombosis, peripheral arterial disease, peripheral arterial thrombosis, urgent peripheral revascularization, peripheral ischemia/gangrene, pulmonary embolism, carotid artery disease, and hemorrhage

$\mathrm{d}$ Including past and current therapies

e csDMARDs: hydroxychloroquine, leflunomide, sulfasalazine, azathioprine, minocycline, and cyclosporine

f Biologics: adalimumab, etanercept, certolizumab pegol, golimumab, infliximab, anakinra, sarilumab, abatacept, rituximab, and tofacitinib

g Among prednisone users

$\mathrm{h}$ Among those experiencing morning stiffness

Questionnaire (mHAQ); and patient-reported pain, fatigue, and morning stiffness.

\section{Statistical Analysis}

Baseline demographics, clinical characteristics, and treatment history were described for the overall cohort. Changes in MTX use were assessed in the overall population and in groups stratified by baseline MTX dose $(\leq 10 \mathrm{mg},>10$ to $\leq 15 \mathrm{mg}$, $>15$ to $\leq 20 \mathrm{mg}$, $>20 \mathrm{mg}$ ). Changes from baseline in disease activity measures and PROs were summarized descriptively for the overall cohort and in groups stratified by MTX discontinuation or dose change at the 6- or 12-month follow-up visit.

\section{RESULTS}

\section{Study Population}

Of 2358 patients with RA who initiated TCZ, 861 continued their existing MTX regimen at TCZ initiation; of those patients, 444 had a 6-month follow-up visit without discontinuation of TCZ and had MTX dose information available at TCZ initiation and follow-up and thus were included in the primary analysis (Fig. 1a). At baseline, 68 patients $(15.3 \%)$ were receiving $\mathrm{MTX} \leq 10 \mathrm{mg}, 110 \quad(24.8 \%)$ were receiving $>10$ to $\leq 15 \mathrm{mg}$, $186(41.9 \%)$ were receiving $>15$ to $\leq 20 \mathrm{mg}$, and $80(18.0 \%)$ were receiving $>20 \mathrm{mg}$ (Fig. 1b). For the secondary analysis, there were 311 eligible patients with a 12-month follow-up visit; of these patients, at baseline, $45 \quad(14.5 \%)$ were receiving MTX $\leq 10 \mathrm{mg}, 78(25.1 \%)$ were receiving $>10$ to $\leq 15 \mathrm{mg}, 134(43.1 \%)$ were receiving $>15$ to $\leq 20 \mathrm{mg}$, and $54 \quad(17.4 \%)$ were receiving $>20 \mathrm{mg}$ (Fig. 1).

\section{Patient Baseline Demographics and Clinical Characteristics}

Patient baseline demographics, clinical characteristics, and treatment history are described in Table 1. Overall, of the 444 patients with a 6-month follow-up visit who met the inclusion criteria for the primary analysis, $82.7 \%$ were female, $83.7 \%$ were white, and the majority (76.4\%) were overweight or obese (Table 1$)$. The mean (SD) age was 57.3 (12.7) years and mean (SD) disease duration was 11.6 (9.3) years. More than half of the patients $(54.1 \%)$ had not received csDMARDs other than MTX, and the majority $(94.1 \%)$ had received $\geq 1$ prior 


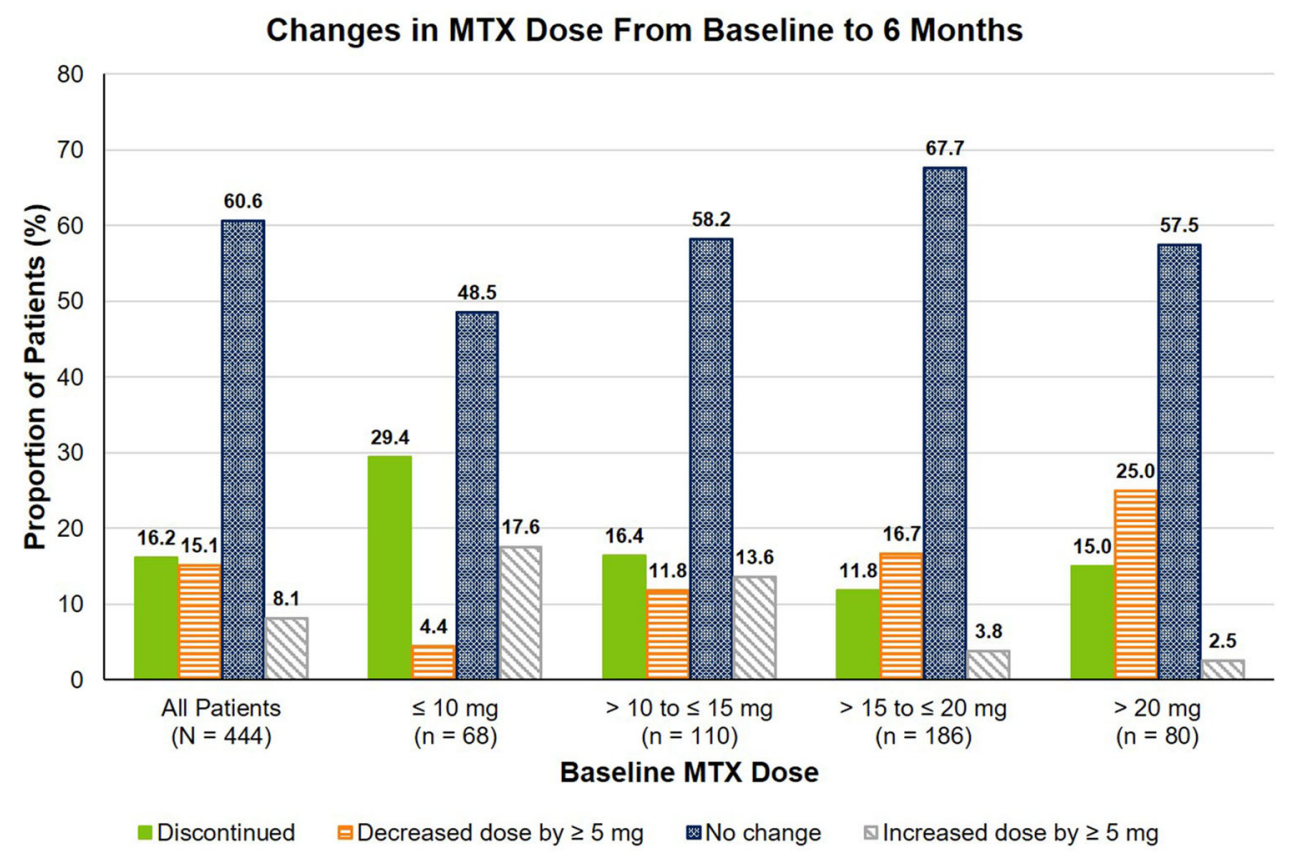

Fig. 2 Changes in MTX dose at 6 months among patients with RA who initiated TCZ with MTX, stratified by baseline MTX dose. $M T X$ methotrexate, $R A$ rheumatoid arthritis, $T C Z$ tocilizumab

biologic. The mean (SD) MTX dose at baseline was 17.7 (5.8) $\mathrm{mg}$. The mean (SD) CDAI score was 24.0 (15.4), and the majority of patients $(89.8 \%)$ reported experiencing morning stiffness.

\section{Changes from Baseline in MTX Use and Disease Activity at 6 Months}

Changes in MTX use, including discontinuation and dose decrease of $\geq 5 \mathrm{mg}$, were observed at 6 months after TCZ initiation. Of the 444 patients initiating TCZ, 139 (31.3\%) discontinued or decreased their dose of MTX by $\geq 5 \mathrm{mg}$ at 6 months, 269 patients $(60.6 \%)$ did not change their dose, and $36(8.1 \%)$ increased their dose by $\geq 5 \mathrm{mg}$ (Fig. 2). The overall mean (SD) change in MTX dose at 6 months was -16.2 (6.0) $\mathrm{mg}$ in patients who discontinued MTX, - 6.4 (4.6) $\mathrm{mg}$ in patients who decreased their MTX dose and - 3.0 (7.5) mg across all patients. Across baseline MTX dose groups, the proportion of patients who discontinued or decreased their dose of MTX ranged from 28.2 to $40.0 \%$ (Fig. 2). Improvements in disease activity and PROs were observed at 6 months in patients who discontinued, decreased, maintained, or increased their dose of MTX (Table 2).

\section{Changes from Baseline in MTX Use and Disease Activity at 12 Months}

Changes in MTX use were also observed at 12 months after initiation of TCZ. Of the 311 patients with a 12-month follow-up visit, 119 (38.3\%) discontinued or decreased their dose of MTX by $\geq 5 \mathrm{mg}, 156$ patients (50.2\%) did not change their dose, and $36(11.6 \%)$ increased their dose by $\geq 5 \mathrm{mg}$ (Fig. 3). The overall mean (SD) change in MTX dose at 12 months was - 17.3 (5.9) $\mathrm{mg}$ in patients who discontinued MTX, - 7.7 (6.2) $\mathrm{mg}$ in patients who decreased their MTX dose and - 3.8 (13.7) mg across all patients. Across baseline MTX dose groups, the proportion of patients who discontinued or decreased their dose of MTX ranged from 35.6 to $42.6 \%$ (Fig. 3). Improvements in disease activity and PROs were observed at 12 months in patients who discontinued, decreased, maintained, or increased their dose of MTX (Table 3). 
Table 2 Changes in disease activity and PROs ${ }^{\mathrm{a}}$ at 6 months in patients with RA who initiated TCZ with MTX

\begin{tabular}{|c|c|c|c|c|c|}
\hline & $\begin{array}{l}\text { All patients } \\
(N=444)\end{array}$ & $\begin{array}{l}\text { Discontinued } \\
\text { MTX }(n=72)\end{array}$ & $\begin{array}{l}\text { Decreased MTX } \\
\text { dose }(n=67)\end{array}$ & $\begin{array}{l}\text { No change in MTX } \\
\text { dose }(n=269)\end{array}$ & $\begin{array}{l}\text { Increased MTX } \\
\text { dose }(n=36)\end{array}$ \\
\hline CDAI & $-7.8(14.3)$ & $-5.5(13.1)$ & $-7.1(13.6)$ & $-8.4(14.7)$ & $-9.8(15.2)$ \\
\hline DAS28 & $-1.2(1.7)$ & $-1.0(1.7)$ & $-1.1(1.5)$ & $-1.3(1.6)$ & $-0.9(2.4)$ \\
\hline Tender joint count & $-3.2(7.9)$ & $-1.3(7.1)$ & $-1.8(7.5)$ & $-3.8(8.1)$ & $-4.2(7.6)$ \\
\hline $\begin{array}{l}\text { Swollen joint } \\
\text { count }\end{array}$ & $-2.6(5.6)$ & $-2.2(5.2)$ & $-2.2(5.1)$ & $-2.7(5.8)$ & $-3.1(6.1)$ \\
\hline $\begin{array}{l}\text { Physician global } \\
\text { assessment }\end{array}$ & $-13.1(23.1)$ & $-13.3(23.4)$ & $-17.0(20.7)$ & $-11.8(23.4)$ & $-16.2(24.0)$ \\
\hline $\begin{array}{c}\text { Patient global } \\
\text { assessment }\end{array}$ & $-7.6(25.9)$ & $-6.4(25.9)$ & $-13.5(28.5)$ & $-6.4(25.0)$ & $-7.3(26.4)$ \\
\hline mHAQ & $-0.1(0.4)$ & $-0.1(0.4)$ & $-0.1(0.4)$ & $0(0.4)$ & $-0.2(0.5)$ \\
\hline Patient pain & $-7.3(24.4)$ & $-6.2(23.7)$ & $-8.2(24.8)$ & $-7.0(24.3)$ & $-10.8(26.2)$ \\
\hline Patient fatigue & $-6.3(26.6)$ & $-7.3(26.5)$ & $-8.6(30.7)$ & $-5.0(26.3)$ & $-10.3(20.2)$ \\
\hline $\begin{array}{l}\text { Morning stiffness } \\
\text { present, } n(\%)\end{array}$ & $-29(7.1)$ & $-6(9.4)$ & $-5(8.2)$ & $-17(6.8)$ & $-1(3.0)$ \\
\hline $\begin{array}{l}\text { Morning stiffness } \\
\text { duration, } h\end{array}$ & $-0.1(3.7)$ & $-0.7(2.8)$ & $0(2.1)$ & $-0.1(3.8)$ & $0.3(6.1)$ \\
\hline
\end{tabular}

$C D A I$ Clinical Disease Activity Index, DAS28 Disease Activity Score in 28 joints, $m H A Q$ modified Health Assessment Questionnaire, $M T X$ methotrexate, $P R O$ patient-reported outcome, $R A$ rheumatoid arthritis, $T C Z$ tocilizumab

${ }^{a}$ Changes in disease activity and PRO measures are presented as mean (SD) unless otherwise indicated

\section{DISCUSSION}

Patients with an inadequate response to csDMARDs are frequently treated with a biologic agent. In most cases, the biologic is administered in combination with the existing csDMARD, which is often MTX [2,3]. However, adherence to such combination therapy may be adversely affected by the increased medication burden and risk of additive toxicities [7-10]. Thus, research is being devoted to understanding treatment patterns and outcomes with biologics administered as monotherapy.

Currently, results on the use of biologic monotherapy stem primarily from clinical trials. In particular, TCZ monotherapy in US-based randomized controlled trials was demonstrated to have superior efficacy compared with MTX monotherapy [16] and tumor necrosis factor (TNF) inhibitor monotherapy [20] and comparable efficacy to TCZ plus MTX combination therapy [15]. These findings are also supported by trials in Japan [21] and Europe [14]. However, there are limited real-world data in the United States regarding whether TCZ can reduce the need for concomitant MTX.

The present analysis aimed to corroborate trial information with real-world evidence by describing the patterns of MTX discontinuation or dose decreases after the initiation of TCZ. We observed that many patients were able to decrease their dose or discontinue use of MTX at both 6 and 12 months after initiating TCZ. These changes were independent of baseline MTX dose, and improvements in disease activity and functionality outcomes were observed in patients who discontinued or decreased MTX.

Our findings are supported by data from additional real-world studies demonstrating 


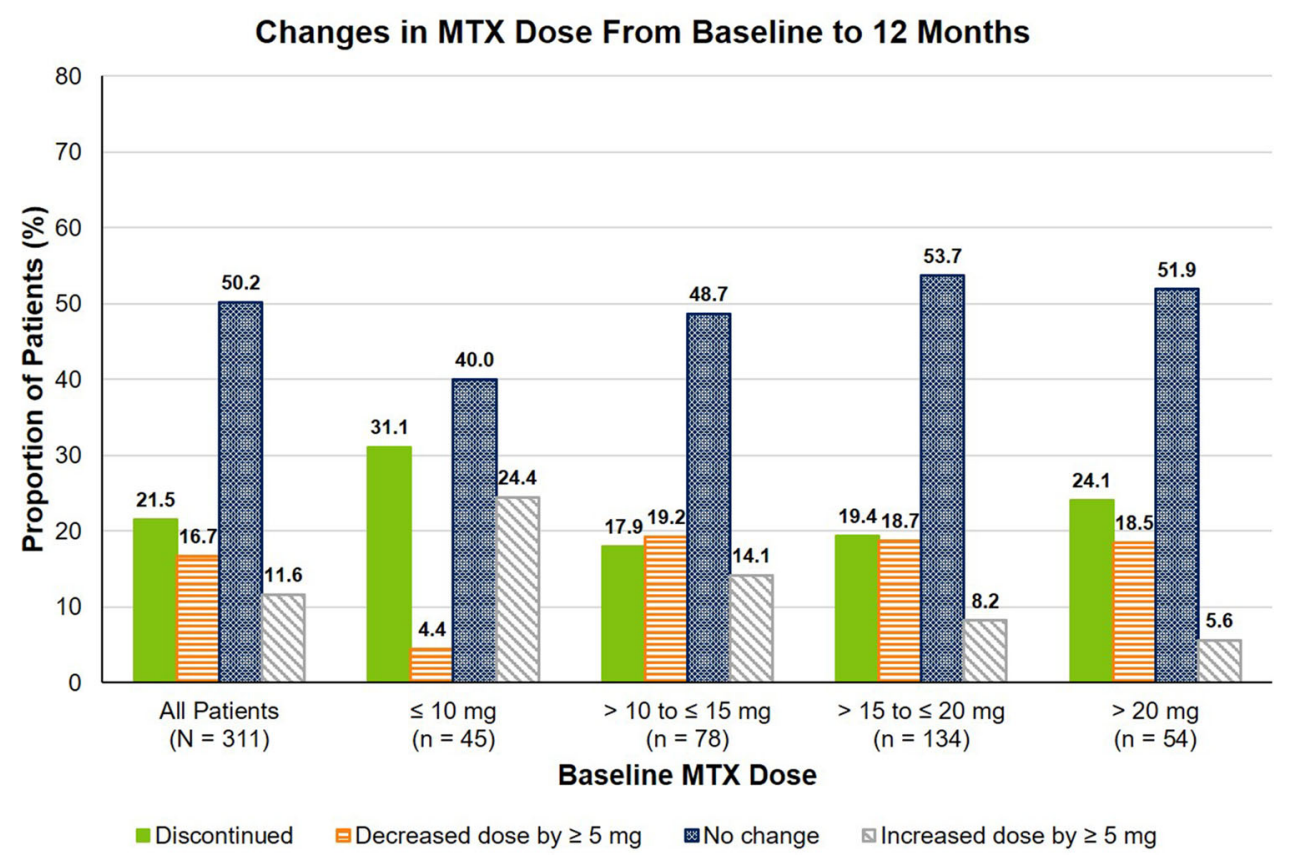

Fig. 3 Changes in MTX dose at 12 months among patients with RA who initiated TCZ with MTX, stratified by baseline MTX dose. $M T X$ methotrexate, $R A$ rheumatoid arthritis, $T C Z$ tocilizumab

discontinuation of MTX in patients with RA after initiation of TCZ plus MTX combination therapy. The Japanese FIRST Bio study demonstrated that, of patients initiating TCZ with concomitant MTX, 19.3\% discontinued MTX by week 52, and the overall mean MTX dose decreased from $9.1 \mathrm{mg}$ to $6.4 \mathrm{mg}$ per week [22]. These results are comparable to the present study, which demonstrated that $21.5 \%$ of patients discontinued MTX at 12 months and the overall mean change in MTX dose at 12 months was - 3.8 (13.7) mg. Additionally, in a multinational observational study of patients with RA initiating TCZ, $47.8 \%$ received concomitant MTX at baseline, whereas $43.0 \%$ received concomitant MTX at month 6; of patients with a change in MTX dose, the mean (SD) dose change was - 2.9 (5.5) $\mathrm{mg}$ per week [23]. Notably, patients in the multinational study had higher baseline disease activity than patients in our study. The present analysis demonstrated that $16.2 \%$ of patients discontinued MTX at 6 months and the overall mean
(SD) dose change at 6 months was -3.0 (7.5) $\mathrm{mg}$.

There are limited data on the efficacy and effectiveness of TCZ after MTX dose decrease or discontinuation. The COMP-ACT trial demonstrated that discontinuation of MTX was noninferior to continuation of MTX for the maintenance of low disease activity (LDA) over 16 weeks [17] in patients with RA who had achieved LDA within 24 weeks of initiating TCZ plus MTX. The Japanese T-ReX trial further demonstrated the clinical feasibility of MTX discontinuation for maintenance of LDA in patients who sustained LDA for $\geq 12$ weeks while receiving TCZ plus MTX combination therapy [24]. Our study sought to address the need for data on the real-world effectiveness of TCZ after MTX dose decrease or discontinuation by evaluating changes in clinical disease activity measures and PROs at both 6 and 12 months in patients seen in routine clinical practice in the United States. The descriptive data provided did not show any apparent increase in disease 
Table 3 Changes in disease activity and PROs ${ }^{a}$ at 12 months in patients with RA who initiated TCZ with MTX

\begin{tabular}{|c|c|c|c|c|c|}
\hline & $\begin{array}{l}\text { All patients } \\
(N=311)\end{array}$ & $\begin{array}{l}\text { Discontinued } \\
\text { MTX }(n=67)\end{array}$ & $\begin{array}{l}\text { Decreased MTX } \\
\text { dose }(n=52)\end{array}$ & $\begin{array}{l}\text { No change in MTX } \\
\text { dose }(n=156)\end{array}$ & $\begin{array}{l}\text { Increased MTX } \\
\text { dose }(n=36)\end{array}$ \\
\hline CDAI & $-8.0(15.0)$ & $-8.6(14.8)$ & $-7.9(12.4)$ & $-7.7(14.3)$ & $-8.1(21.3)$ \\
\hline DAS28 & $-1.2(1.8)$ & $-1.0(1.5)$ & $-1.1(1.5)$ & $-1.4(1.8)$ & $-1.0(2.7)$ \\
\hline Tender joint count & $-3.1(8.3)$ & $-3.8(6.9)$ & $-2.4(6.0)$ & $-3.1(9.2)$ & $-3.1(9.9)$ \\
\hline $\begin{array}{l}\text { Swollen joint } \\
\text { count }\end{array}$ & $-2.6(5.8)$ & $-2.2(6.4)$ & $-2.7(5.1)$ & $-2.6(4.9)$ & $-2.8(8.6)$ \\
\hline $\begin{array}{l}\text { Physician global } \\
\text { assessment }\end{array}$ & $-14.9(22.4)$ & $-16.0(21.8)$ & $-18.2(21.6)$ & $-13.1(21.8)$ & $-15.8(27.4)$ \\
\hline $\begin{array}{c}\text { Patient global } \\
\text { assessment }\end{array}$ & $-9.3(25.1)$ & $-9.7(24.9)$ & $-9.6(29.4)$ & $-9.6(22.0)$ & $-6.5(31.5)$ \\
\hline mHAQ & $0(0.4)$ & $0(0.4)$ & $-0.1(0.4)$ & $0(0.3)$ & $-0.1(0.6)$ \\
\hline Patient pain & $-8.0(25.3)$ & $-8.0(26.9)$ & $-6.8(29.2)$ & $-8.3(22.1)$ & $-8.6(30.4)$ \\
\hline Patient fatigue & $-8.5(25.9)$ & $-10.8(24.9)$ & $-5.9(31.4)$ & $-7.8(24.3)$ & $-11.3(26.9)$ \\
\hline $\begin{array}{c}\text { Morning stiffness } \\
\text { present, } n(\%)\end{array}$ & $-18(6.3)$ & $-1(1.7)$ & $-3(6.5)$ & $-14(9.6)$ & $0(0)$ \\
\hline $\begin{array}{l}\text { Morning stiffness } \\
\text { duration, } h\end{array}$ & $-0.3(2.6)$ & $-0.3(3.1)$ & $0.1(1.5)$ & $-0.4(2.8)$ & $-0.3(1.3)$ \\
\hline
\end{tabular}

CDAI Clinical Disease Activity Index, DAS28 Disease Activity Score in 28 joints, $m H A Q$ modified Health Assessment Questionnaire, $M T X$ methotrexate, $P R O$ patient-reported outcome, $R A$ rheumatoid arthritis, $T C Z$ tocilizumab

${ }^{a}$ Changes in disease activity and PRO measures are presented as mean (SD) unless otherwise indicated

activity in patients who discontinued or decreased their dose of MTX.

In patients receiving anti-TNF antibodies (aTNFs), discontinuation of MTX is contraindicated because MTX inhibits antidrug antibody formation against aTNFs, thereby resulting in loss of efficacy [25]. However, there is reason to believe that discontinuation of MTX may be more successful with therapies that inhibit IL-6, such as TCZ. It has been demonstrated that MTX itself inhibits IL-6 [26], making it possible to posit that, in patients responding to TCZ plus MTX, the relative contribution of IL- 6 inhibition from TCZ is far greater than it is from MTX. Thus, the loss of IL-6 inhibition upon MTX discontinuation may have a lesser impact on response in patients receiving TCZ plus MTX than in those receiving aTNF plus MTX.
A strength of this real-world study is the large number of patients included, which was possible through use of the Corrona RA registry. Corrona is the largest RA registry in the United States that collects data directly from both physicians and patients at the time of a routine clinical encounter. This design allowed us to evaluate outcomes at multiple time points. Additionally, rheumatology practices from across the United States participate in the Corrona RA registry, including practices in both rural and urban areas and academic and private settings, which provides access to patients of diverse socioeconomic backgrounds. It has been shown that Medicare beneficiaries with RA in the Corrona Registry have a comparable demographic profile and comorbidity burden to the overall US Medicare RA population, which 
supports the generalizability of the findings from the Corrona RA Registry [19].

As with other observational studies, this study has some limitations. As is the case with all registry data, there is the possibility of a channeling bias for the choice of therapeutic agent as participants are not randomly assigned to different treatments. Additionally, because the goal of this analysis was to examine changes in MTX use after TCZ initiation in a real-world setting and not to evaluate associations between initial MTX dose and subsequent changes in MTX dose or discontinuation, this study presented descriptive data without matching patients or adjusting for statistical imbalances between the different patient groups; future studies would be needed to examine such associations. Patients who discontinued TCZ for any reason were excluded; thus, our primary analysis demonstrated the changes in MTX dose for patients who tolerated TCZ treatment and did not discontinue for 6 months, while the secondary analysis demonstrated outcomes for patients who did not discontinue for 12 months. Therefore, these findings may not be generalizable for patients who discontinue TCZ before 6 or 12 months.

\section{CONCLUSIONS}

In this real-world population of patients with RA, a substantial proportion of patients initiating TCZ were able to discontinue or decrease their dose of MTX over 6 months after TCZ initiation, with similar changes in MTX dose at 12 months. Discontinuation or dose decrease of MTX was observed across all baseline MTX doses. Disease activity and PRO improvements were observed at 6 or 12 months in patients who decreased or discontinued MTX. These results suggest that discontinuation or decreases in the dose of MTX after initiation of TCZ are common in real-world practice.

\section{ACKNOWLEDGEMENTS}

The authors thank the participating providers and patients for contributing data to the Corrona RA Registry.

Funding. This study was sponsored by Corrona, LLC, and the analysis was funded by Genentech, Inc. Access to study data was limited to Corrona, and Corrona statisticians completed all of the analyses; all authors contributed to the interpretation of the results. Corrona has been supported through contracted subscriptions in the last 2 years by AbbVie, Amgen, Boehringer Ingelheim, Bristol Myers Squibb, Celgene, Crescendo, Eli Lilly and Company, Genentech, Inc., Gilead, GSK, Janssen, Merck, Momenta Pharmaceuticals, Novartis, Ortho Dermatologics, Pfizer Inc, Regeneron, Roche, Sun, and UCB. The Rapid Service Fee was funded by Genentech, Inc.

Medical Writing Assistance. Support for third-party writing assistance, furnished by Claire Stedden, PhD, of Health Interactions, Inc, was provided by Genentech, Inc.

Authorship. All named authors meet the International Committee of Medical Journal Editors (ICMJE) criteria for authorship for this article, take responsibility for the integrity of the work as a whole, and have given their approval for this version to be published.

Prior Presentation. A portion of this data was presented at the 2019 EULAR Annual European Congress of Rheumatology, June 12-15, Madrid, Spain, and at the 2019 ACR Annual Meeting, November 8-13, Atlanta, GA, USA.

Disclosures. Dimitrios A. Pappas is an employee and shareholder of Corrona, LLC, and a consultant for Regeneron, Novartis, and Roche. Taylor Blachley is an employee of Corrona, LLC. Kelechi Emeanuru is an employee of Corrona, LLC. Steve Zlotnick is an employee and shareholder of Genentech, Inc. Jennie Best is an employee and shareholder of Genentech, Inc. Joel $M$. Kremer is an employee and 
shareholder of Corrona, LLC, and a consultant for AbbVie, Amgen, Bristol Myers Squibb, Genentech, Inc., Gilead, GSK, Lilly, Pfizer, Regeneron, and Sanofi.

Compliance with Ethics Guidelines. Ethics approvals for this study were obtained from a central institutional review board (IRB; New England Independent Review Board No. 120160610). For academic investigative sites that did not receive a waiver to use the central IRB, full board approval was obtained from the respective governing IRBs and documentation of approval was submitted to the sponsor prior to initiating any study procedures. All procedures performed in studies involving human participants were in accordance with the ethical standards of the institutional and/or national research committee and with the 1964 Helsinki Declaration and its later amendments or comparable ethical standards. Informed consent was obtained from all individual participants included in the study.

Data Availability. The datasets generated and analyzed during the current study are not publicly available because of proprietary rights but are available from the corresponding author on reasonable request.

Open Access. This article is licensed under a Creative Commons Attribution-NonCommercial 4.0 International License, which permits any noncommercial use, sharing, adaptation, distribution and reproduction in any medium or format, as long as you give appropriate credit to the original author(s) and the source, provide a link to the Creative Commons licence, and indicate if changes were made. The images or other third party material in this article are included in the article's Creative Commons licence, unless indicated otherwise in a credit line to the material. If material is not included in the article's Creative Commons licence and your intended use is not permitted by statutory regulation or exceeds the permitted use, you will need to obtain permission directly from the copyright holder. To view a copy of this licence, visit http://creativecommons.org/ licenses/by-nc/4.0/.

\section{REFERENCES}

1. Aletaha D, Neogi T, Silman AJ, Funovits J, Felson DT, Bingham CO 3rd, et al. 2010 Rheumatoid arthritis classification criteria: an American College of Rheumatology/European League Against Rheumatism collaborative initiative. Arthritis Rheum. 2010;62(9):2569-81.

2. Smolen JS, Landewe R, Bijlsma J, Burmester G, Chatzidionysiou K, Dougados $\mathrm{M}$, et al. EULAR recommendations for the management of rheumatoid arthritis with synthetic and biological diseasemodifying antirheumatic drugs: 2016 update. Ann Rheum Dis. 2017;76(6):960-77.

3. Singh JA, Saag KG, Bridges SL Jr, Akl EA, Bannuru RR, Sullivan MC, et al. 2015 American College of Rheumatology guideline for the treatment of rheumatoid arthritis. Arthritis Care Res (Hoboken). 2016;68(1):1-25.

4. Schnabel A, Reinhold-Keller E, Willmann V, Gross WL. Tolerability of methotrexate starting with 15 or $25 \mathrm{mg} /$ week for rheumatoid arthritis. Rheumatol Int. 1994;14(1):33-8.

5. Verstappen SM, Jacobs JW, van der Veen MJ, Heurkens AH, Schenk Y, Borg EJ, et al. Intensive treatment with methotrexate in early rheumatoid arthritis: aiming for remission. Computer assisted management in early rheumatoid arthritis (CAMERA, an open-label strategy trial). Ann Rheum Dis. 2007;66(11):1443-9.

6. Albrecht K, Müller-Ladner U. Side effects and management of side effects of methotrexate in rheumatoid arthritis. Clin Exp Rheumatol. 2010;28(5 Suppl 61):S95-101.

7. Salt E, Frazier SK. Predictors of medication adherence in patients with rheumatoid arthritis. Drug Dev Res. 2011;72(8):756-63.

8. Agarwal S, Zaman T, Handa R. Retention rates of disease-modifying anti-rheumatic drugs in patients with rheumatoid arthritis. Singapore Med J. 2009;50(7):686-92.

9. Bonafede M, Johnson BH, Tang DH, Shah N, Harrison DJ, Collier DH. Etanercept-methotrexate combination therapy initiators have greater adherence and persistence than triple therapy initiators with rheumatoid arthritis. Arthritis Care Res (Hoboken). 2015;67(12):1656-63.

10. Lyles A, Culver N, Ivester J, Potter T. Effects of health literacy and polypharmacy on medication adherence. Consult Pharm. 2013;28(12):793-9. 
11. de Achaval S, Suarez-Almazor ME. Treatment adherence to disease-modifying antirheumatic drugs in patients with rheumatoid arthritis and systemic lupus erythematosus. Int J Clin Rheumtol. 2010;5(3):313-26.

12. Fidder $H H$, Singendonk $M M$, van der Have $M$, Oldenburg B, van Oijen MG. Low rates of adherence for tumor necrosis factor- $\alpha$ inhibitors in Crohn's disease and rheumatoid arthritis: results of a systematic review. World J Gastroenterol. 2013;19(27):4344-50.

13. Genentech Inc. ACTEMRA prescribing information. South San Francisco: Genentech Inc; 2019.

14. Maini RN, Taylor PC, Szechinski J, Pavelka K, Broll J, Balint $\mathrm{G}$, et al. Double-blind randomized controlled clinical trial of the interleukin-6 receptor antagonist, tocilizumab, in European patients with rheumatoid arthritis who had an incomplete response to methotrexate. Arthritis Rheum. 2006;54(9):2817-29.

15. Dougados M, Kissel K, Sheeran T, Tak PP, Conaghan PG, Mola EM, et al. Adding tocilizumab or switching to tocilizumab monotherapy in methotrexate inadequate responders: 24-week symptomatic and structural results of a 2-year randomised controlled strategy trial in rheumatoid arthritis (ACT-RAY). Ann Rheum Dis. 2013;72(1):43-50.

16. Jones G, Sebba A, Gu J, Lowenstein MB, Calvo A, Gomez-Reino JJ, et al. Comparison of tocilizumab monotherapy versus methotrexate monotherapy in patients with moderate to severe rheumatoid arthritis: the AMBITION study. Ann Rheum Dis. 2010;69(1):88-96.

17. Kremer JM, Rigby W, Singer NG, Birchwood C, Gill $\mathrm{D}$, Reiss $\mathrm{W}$, et al. Sustained response following discontinuation of methotrexate in patients with rheumatoid arthritis treated with subcutaneous tocilizumab: results from a randomized, controlled trial. Arthritis Rheumatol (Hoboken). 2018;70(8): 1200-8.

18. Kremer JM. The Corrona US registry of rheumatic and autoimmune diseases. Clin Exp Rheumatol. 2016;34(5 Suppl 101):S96-9.

19. Curtis JR, Chen L, Bharat A, Delzell E, Greenberg JD, Harrold L, et al. Linkage of a de-identified United
States rheumatoid arthritis registry with administrative data to facilitate comparative effectiveness research. Arthritis Care Res (Hoboken). 2014;66(12):1790-8.

20. Gabay C, Emery P, van Vollenhoven R, Dikranian A, Alten R, Pavelka $\mathrm{K}$, et al. Tocilizumab monotherapy versus adalimumab monotherapy for treatment of rheumatoid arthritis (ADACTA): a randomised, double-blind, controlled phase 4 trial. Lancet. 2013;381(9877):1541-50.

21. Nishimoto N, Miyasaka N, Yamamoto K, Kawai S, Takeuchi T, Azuma J, et al. Study of active controlled tocilizumab monotherapy for rheumatoid arthritis patients with an inadequate response to methotrexate (SATORI): significant reduction in disease activity and serum vascular endothelial growth factor by IL-6 receptor inhibition therapy. Mod Rheumatol. 2009;19(1):12-9.

22. Ishiguro N, Atsumi T, Harigai M, Mimori T, Nishimoto N, Sumida T, et al. Effectiveness and safety of tocilizumab in achieving clinical and functional remission, and sustaining efficacy in biologicsnaive patients with rheumatoid arthritis: the FIRST Bio study. Mod Rheumatol. 2017;27(2):217-26.

23. Haraoui B, Casado G, Czirják L, Taylor A, Dong L, Button P, et al. Tocilizumab patterns of use, effectiveness, and safety in patients with rheumatoid arthritis: final results from a set of multi-national non-interventional studies. Rheumatol Ther. 2019;6(2):231-43.

24. Asai S, Hayashi M, Hanabayashi M, Kanayama Y, Takemoto $\mathrm{T}$, Yabe $\mathrm{Y}$, et al. Discontinuation of concomitant methotrexate in Japanese patients with rheumatoid arthritis treated with tocilizumab: an interventional study. Mod Rheumatol. 2019;7: $1-8$.

25. Dervieux T, Weinblatt ME, Kivitz A, Kremer JM. Methotrexate polyglutamation in relation to infliximab pharmacokinetics in rheumatoid arthritis. Ann Rheum Dis. 2013;72(6):908-10.

26. Kremer JM, Lawrence DA, Hamilton R, McInnes IB. Long-term study of the impact of methotrexate on serum cytokines and lymphocyte subsets in patients with active rheumatoid arthritis: correlation with pharmacokinetic measures. RMD Open. 2016;2(1):e000287-2016. 